\title{
Analysis of wind events in a coastal area: a tool for assessing turbulence variability for studies on plankton*
}

\author{
ÒSCAR GUADAYOL and FRANCESC PETERS
}

Institut de Ciències del Mar, CMIMA (CSIC), P. Marítim de la Barceloneta 37-49, 08003 Barcelona, Catalunya, Spain. E-mail: osguad@icm.csic.es

\begin{abstract}
SUMMARY: Turbulence at different scales, from generation to dissipation, influences planktonic communities. Many experimental studies have recently been done to determine the effects of small-scale turbulence on plankton, but it is difficult to state the relevance of the findings since there is little unbiased information on turbulence variability in the sea. In this study, we use wind velocity data series from several meteorological stations located along the Catalan coast to estimate the spatial and temporal variability of small-scale turbulence in the upper ocean. Using a peaks-over-threshold approach, we develop a statistical model to assess the frequency of wind events as a function of their persistence and intensity. Finally, the wind speed data series are converted into turbulent energy dissipation rate estimates at $1 \mathrm{~m}$ depth to determine the general distribution of turbulence on the Catalan coast. Geographical variability is larger than seasonal variability in frequency and persistence of wind events, owing to differences in local relief. These statistical models developed for wind events combined with empirical relationships between wind and turbulence, are tools for estimating the occurrence and persistence of turbulent events at a given location and season. They serve to put into context the past, present and future studies of the effects of turbulence on coastal planktonic organisms and processes.
\end{abstract}

Keywords: wind events, small-scale turbulence, plankton, peaks-over-threshold approach.

RESUMEN: ANÁLISIS DE EPISODIOS DE VIENTO EN UN ÁREA COSTERA: UNA HERRAMIENTA PARA LA ESTIMACIÓN DE LA VARIABILIDAD EN LA TURBULENCIA EN ESTUDIOS CON PLANCTON. - La turbulencia a diferentes escalas, desde su generación a su disipación, afecta a la comunidad planctónica. Recientemente el interés por los efectos de la turbulencia de escala pequeña se ha desarrollado mucho, pero es difícil establecer la importancia de tales estudios, puesto que no hay información completa de la variabilidad de la turbulencia en el mar. En el presente trabajo, usamos series de datos de viento provenientes de diversas estaciones meteorológicas situadas a lo largo del litoral catalán para estudiar la variabilidad espacio-temporal de la turbulencia de escala pequeña. Mediante una aproximación POT ("peaks-over-threshold"), desarrollamos un modelo estadístico para estimar la frecuencia de episodios de viento, en función de su persistencia e intensidad. Los datos de velocidad de viento son utilizados para estimar las tasas de disipación de la energía turbulenta a 1 metro de profundidad, con el fin de determinar la distribución general de la turbulencia en la costa catalana. Debido al relieve local, la variabilidad geográfica es mayor que la estacional en la frecuencia y persistencia de episodios de viento. El modelo estadístico desarrollado, junto con relaciones empíricas entre viento y turbulencia, pueden ser usados para estimar la ocurrencia y frecuencia de episodios en una localidad y estación dadas. Sirven para poner en contexto estudios pasados, presentes y futuros sobre los efectos de la turbulencia en el plancton.

Palabras clave: episodios de viento, turbulencia de pequeña escala, plancton, POT. 


\section{INTRODUCTION}

Marine plankton is generally small, below ca. 1 $\mathrm{cm}$, and has characteristic time scales for its life cycles and energy and matter acquisition processes that range from minutes to weeks. During the past few decades, turbulence has been shown to influence planktonic organisms and processes at different temporal and spatial scales. At the larger scales, there is a redistribution of the populations and their resources. For example frontal zones (Holligan, 1981), upwelling areas (Csanady, 1989), and internal waves (Pingree et al., 1981; Dietze et al., 2004), increase nutrients from nutrient rich water masses mixing into waters where light is available to facilitate primary production. Turbulence also influences horizontal transport, sedimentation (Ruiz, 1996; Ruiz et al., 2004) and resuspension of particles. At smaller scales, turbulence and the shear derived from it affect the flux of solutes to and away from microscopic particles (Lazier and Mann, 1989; Karp-Boss et al., 1996), and the encounter probability between particles (Rothschild and Osborn, 1988). Thus, it influences nutrient uptake (Karp-Boss et al., 1996; Maar et al., 2002), particle feeding processes (Marrasé et al., 1990; Saiz and Kiørboe, 1995; Mackenzie and Kiørboe, 2000), mating (Yen et al., 1998), and aggregation/disaggregation processes (Kiørboe, 1997).

Experimental efforts on this topic have been focused mainly on determining turbulence threshold values that trigger a response in plankton. Most of this empirical knowledge comes from laboratory studies under controlled and generally constant turbulence levels (Peters and Redondo, 1996; Peters and Marrasé, 2000). However, turbulence is highly variable both in space and time. Thus, in order to better understand the roles of small-scale turbulence in plankton dynamics, it is necessary to know the frequency, intensity and duration of turbulence events. Direct measurements of turbulence in the ocean have been carried out with specialized sensors, such as free-falling airfoil probes (Osborn and Crawford, 1980). However, measurements are scattered both in space and time and require relatively calm sea conditions, which may bias bulk turbulence estimations. More recently, acoustic Doppler velocimeters have become available to be moored for long term small-scale turbulence measurements (e.g. Gargett and Donaghay, 2003). In order to extract annual variability in turbulence it is necessary to have at least several years of continuous data, which does not seem to be available yet.
The main mechanical energy input into the upper layer of the ocean is due to wind, mostly directly through shear induced by wind stress on the ocean surface. Turbulent kinetic energy dissipation in the upper layer of the ocean has been described by a boundary layer model, in which dissipation rates near the sea surface layer depend only on wind velocity and distance from the boundary (e.g. Turner, 1973). In the uppermost layer -the so called wave-affected-surface-layer (WASP) - the dissipation rates are enhanced with respect to the boundary layer model due to wavebreaking (Terray et al., 1996; Gemmrich and Farmer, 1999; Gemmrich and Farmer, 2004; Stips et al. 2005), especially for very strong winds and high waves. Mechanisms such as Langmuir circulations (Gargett, 1989; D'Asaro and Dairiki, 1997; McWilliams et al., 1997), upwelling (Csanady, 1989; Dewey and Moum, 1990), tides (St. Laurent et al., 2002), internal waves (Sun and Kunze, 1999) and others may participate in the energy input process. However, in areas with low tidal energy input $(25 \mathrm{~cm}$ at maximum height in the Catalan coast) wind alone may be a reasonably good, although conservative, predictor of mean turbulence. Empirical models that relate wind speed over water with turbulence at a certain depth (Mackenzie and Leggett, 1993), can successfully explain dissipation data found in the literature even in conditions where wind is not the only possible direct source of turbulence since the data used to generate the models is inherently affected by such processes. These models can provide long records of the spatial and temporal variability of turbulence quickly and easily, given that meteorological data is their input.

The aim of this study was to determine the bulk variability of turbulence in the upper layer of a coastal zone. We used wind velocity data series from several meteorological stations located along the Catalan coast (NW Mediterranean) to assess the spatial and temporal distribution of events in this area. It is not the purpose of this paper to predict specific turbulence events in a weather forecast-like fashion.

\section{METHODS}

\section{Data}

Wind data series were obtained from 5 automatic meteorological stations of the Catalan Meteorological 


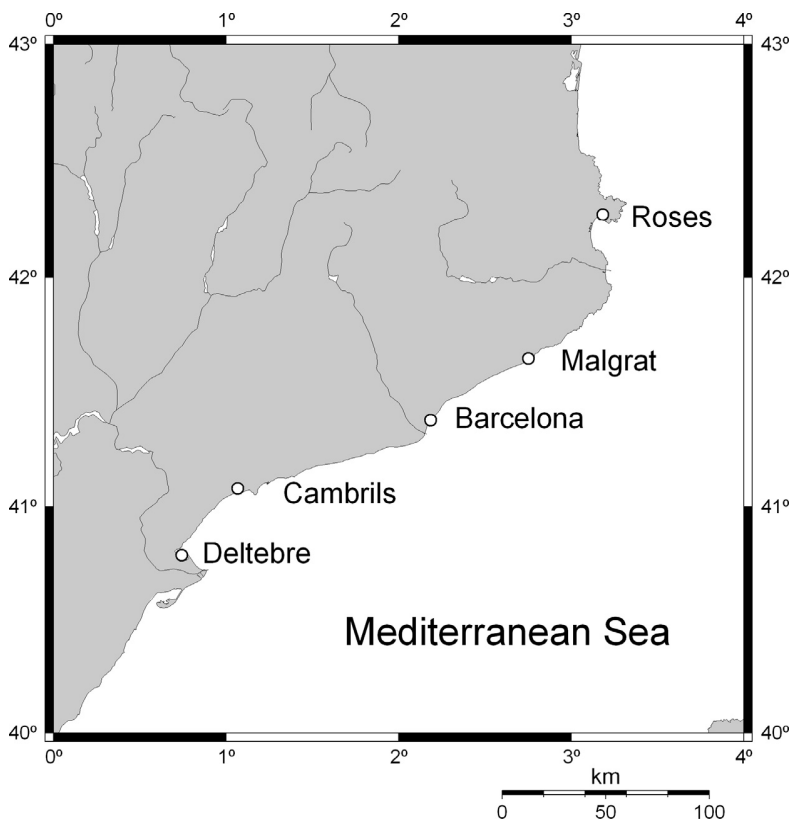

FIG. 1. - Map of the Catalan coast showing the locations analyzed in this study.

Service (SMC, http://www.meteocat.net) and of Puertos del Estado (http://www.puertos.es/) located on land along the Catalan coast, (Fig. 1, additional info in Table 1). The temporal distribution and length of the series are shown in Table 2.

The stations recorded, among other meteorological parameters, wind speed $\left(\mathrm{m} \cdot \mathrm{s}^{-1}\right)$ and direction (degrees) as the vectorial average of the instantaneous values over hourly or half hourly intervals.
When provided with a half hour frequency, we computed the hourly average. The minimum period of constant wind direction blowing in order to produce fully developed turbulence is still a matter of discussion. Nevertheless, there is some consensus that turbulence increases within one hour of increased wind speed (Dewey and Moum, 1990). Oakey and Elliot (1982) also found a good correlation between turbulence measurements and the previous hourly averaged wind. Thus, using one hour averages seems to be consistent with the mechanics of generating wind-induced turbulence.

In order to detect possible long-term changes in anemometer conditions owing to malfunctioning or to changes in the surrounding terrain, moving averages of wind speed with a window of 90 days were plotted and examined. The series did not show any trend for any of the locations during the several years which the study covered.

Meteorological stations were chosen according to several criteria: 1) shortest distance to the coastline, 2) low height of location, 3) terrain as homogeneous and smooth as possible in order to have a low aerodynamic roughness length (the height where the wind speed becomes zero (Stull, 1988)), and 4) a relatively even distribution along the coast studied.

Anemometers were positioned at 2 or 10 meters above the ground (Table 1). Wind speed data obtained at 2 meters were rescaled to $10 \mathrm{~m}$ using the logarithmic wind profile (Stull, 1988):

TABLE 1. - Information on the meteorological stations used in this study.

\begin{tabular}{|c|c|c|c|c|c|c|}
\hline Location & Latitude & Longitude & $\begin{array}{l}\text { Distance to } \\
\text { coastline }\end{array}$ & $\begin{array}{l}\text { Station } \\
\text { height }\end{array}$ & $\begin{array}{l}\text { Anemometer } \\
\text { height }\end{array}$ & Source \\
\hline Roses & $42^{\circ} 16^{\prime} 14^{\prime \prime} \mathrm{N}$ & $3^{\circ} 10^{\prime} 57^{\prime \prime} \mathrm{E}$ & $810 \mathrm{~m}$ & $24 \mathrm{~m}$ & $10 \mathrm{~m}$ & SMC \\
\hline Malgrat de Mar & $41^{\circ} 38^{\prime} 57^{\prime \prime N}$ & $2^{\circ} 45^{\prime} 8^{\prime \prime} \mathrm{E}$ & $520 \mathrm{~m}$ & $4 \mathrm{~m}$ & $2 \mathrm{~m}$ & SMC \\
\hline Barcelona Harbour & $41^{\circ} 22^{\prime} 51^{\prime \prime N} \mathrm{~N}$ & $2^{\circ} 11$ '7’E & $570 \mathrm{~m}$ & - & $11 \mathrm{~m}$ & Puertos del Estado \\
\hline Cambrils-Vinyols i els Arcs & $41^{\circ} 04^{\prime} 51^{\prime \prime N} \mathrm{~N}$ & $1^{\circ} 03,58^{\prime \prime} \mathrm{E}$ & $1690 \mathrm{~m}$ & $24 \mathrm{~m}$ & $2 \mathrm{~m}$ & SMC \\
\hline Deltebre-el Fangar & $40^{\circ} 47^{\prime} 16^{\prime \prime} \mathrm{N}$ & 044’30”'E & $70 \mathrm{~m}$ & $1 \mathrm{~m}$ & $2 \mathrm{~m}$ & SMC \\
\hline
\end{tabular}

TABLE 2. - Temporal distribution and length of series of wind data.

\begin{tabular}{|c|c|c|c|c|c|c|c|c|c|c|c|c|c|c|c|c|c|}
\hline Location & 1990 & 1991 & 1992 & 1993 & 1994 & 1995 & 1996 & 1997 & 199 & 199 & 20 & 000 & 20 & & 20 & & 2003 \\
\hline Roses & & & & & & & & & & & & & & & & & \\
\hline Malgrat & & & & & & & & & & & & & & & & & \\
\hline Barcelona & & & & & & & & & & & & & & & & & \\
\hline Cambrils & & & & & & & & & & & & & & & & & \\
\hline Deltebre & & & & & & & & & & & & & & & & & \\
\hline
\end{tabular}




$$
\bar{M}_{10}=\bar{M}_{n} \frac{\log \left(10 / z_{0}\right)}{\log \left(n / z_{0}\right)},
$$

where the mean velocity at a height of $n$ meters is $\bar{M}_{n}$ and the aerodynamic roughness length is $z_{0}$. The aerodynamic roughness length was assumed to be $0.03 \mathrm{~m}$, corresponding to roughness class 1 , i.e. open agricultural areas without fences and hedgerows, very scattered buildings and only softly rounded hills (Troen and Petersen, 1989).

The integrity of the time series was studied and gaps of 2 hours or less were linearly interpolated. The longest acceptable interpolation was determined as follows. One year of data without any gaps was selected. Gaps of increasing length (from 1 to 12 hours) were introduced into the series and interpolated linearly. Coefficients of determination $\left(\mathrm{r}^{2}\right)$ were calculated between the interpolated values and the real values. For 2 hour long gaps, the $\mathrm{r}^{2}$ was acceptably good (about 75\%).

\section{Wind events analysis}

Wind data series were divided into four 3 months seasons, i.e. winter (January, February and March), spring (April, May and June), summer (July, August and September), and autumn (October, November and December).

A peaks-over-threshold (POT) approach was used to assess the number, intensity and persistence of wind events. Events were defined as parts of the temporal series in which all the measurements of wind speed were over the given threshold. This kind of approach is common in statistics of extreme values, but here the aim was not to determine the occurrence of the extreme events but the general structure of all kinds of events. Therefore, a wide range of thresholds was used rather than just one.

For each geographical series and seasonal subseries an analysis was conducted to determine the number, intensity and persistence of wind events. A routine was designed to find events over thresholds which ranged from the mean value of the given series to $15 \mathrm{~m} \mathrm{~s}^{-1}$, in intervals of $0.1 \mathrm{~m} \mathrm{~s}^{-1}$, which was the resolution of the anemometers. In order to register an event it had to be complete, that is, it could not contain missing values, nor start or end with a gap; otherwise, the event was rejected. When calculating the frequency of events, these rejections were taken into account and subtracted from the length of the series.
The arithmetic mean speed of each detected event and its persistence expressed as the number of hours the event lasted, was computed and recorded. For a given threshold, and for every persistence class $p$, frequency $(f)$ of events was calculated as follows:

$$
f=\frac{1}{l} \sum_{p=i}^{p \max } N_{i},
$$

where $L$ is length of series expressed in seasons or in years, $p$ is persistence class, $p_{\max }$ is maximum observed persistence for that particular threshold, and $N_{i}$ is number of events of persistence $i$. Thus, frequency expresses the number of events over a given threshold that persist al least $p$ hours.

\section{Turbulence data}

Model 6 in Mackenzie and Leggett (1993) was used to convert wind speed into the turbulent kinetic energy dissipation rate $(\varepsilon)$ :

$$
\log _{10} \varepsilon=2.688 \log _{10} U-1.322 * \log _{10} z-4.812
$$

where $\varepsilon$ is in $\mathrm{W} \cdot \mathrm{m}^{-3}, U$ is wind velocity in $\mathrm{m} \mathrm{s}^{-1}$ and $z$ is depth in $m$.

We used model 6 in Mackenzie and Leggett (1993) since it is the most general model given by these authors. It was developed using data from very different hydrographical situations, including coastal zones where the wind was not the only possible source of surface turbulence. This multiple regression model was originally generated from vertical $\varepsilon$ profiles and daily averaged wind speed from the literature. Therefore, in order to apply it, daily averages of wind speed were used instead of the one hour frequency original data. Depth in this study was 1 meter. We chose $1 \mathrm{~m}$ because many studies of turbulence effects on plankton have been carried out with surface-subsurface water and therefore we considered it to be the most relevant. Other depths may be plugged into Eq. 3 at convenience. Statistical analyses were done using the Statistica 6 software package. From now on $\varepsilon$ will be expressed in units of $\mathrm{cm}^{2} \cdot \mathrm{s}^{-3}$.

\section{RESULTS}

\section{General wind conditions}

There are several characteristic synoptic situations in the north-western Mediterranean (Reiter, 
A

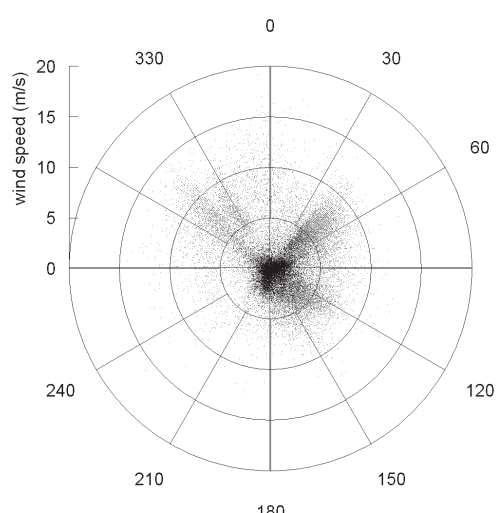

C

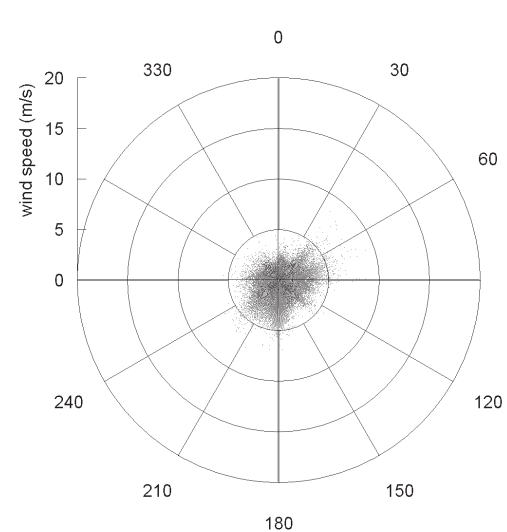

E

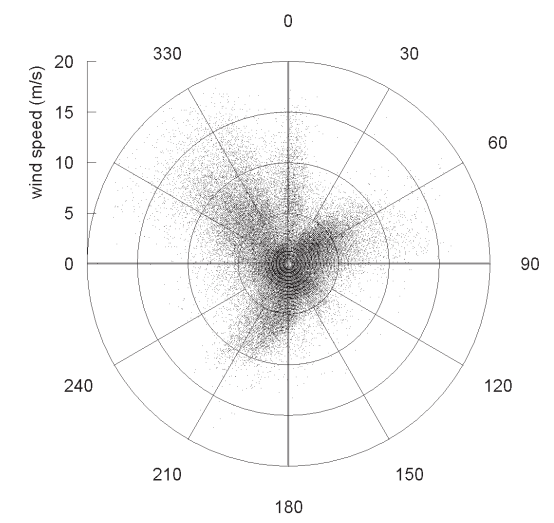

B

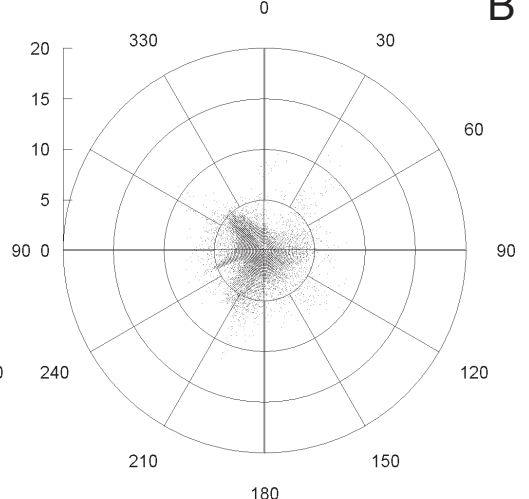

180

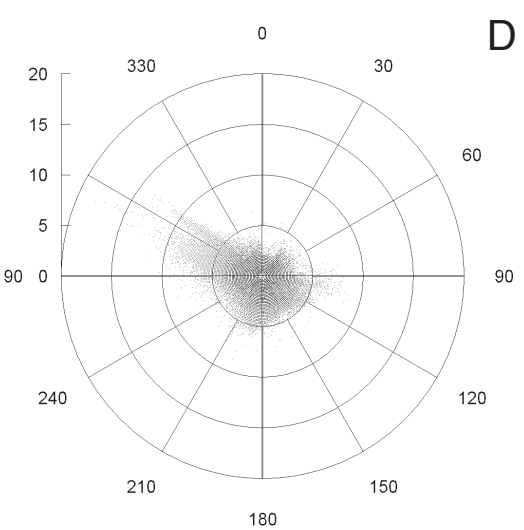

9

D

(1)

FIG. 2. - Polar plots of wind intensity and direction for each location: Roses (A), Malgrat (B), Barcelona (C), Cambrils (D), and Deltebre (E).

1975). The more intense and persistent winds are land winds which blow from the $\mathrm{N}$ or NW channelled through the coastal mountain ranges. They are connected with the advance of an anticyclone from the west following a depression in the Mediterranean. The E and NE wind ("llevants") are very strong and characteristic in storm conditions ("llevantades") which are often associated with a depression in the south-western Mediterranean. "Garbins" are southwesterlies originating as strong SE sea breezes, modified by the Coriolis effect. These southwesterlies are moderate winds that are typical in the summer and blow when a high pressure system embraces southern Europe and the
Mediterranean and also under similar calm weather situations.

Polar plots for each location (Fig. 2) show this general pattern to some degree, but there is geographical variability both in direction and speed along the Catalan coast. This general pattern generated by synoptic situations is altered at each location because of local relief (García and Ballester, 1984). It affects not only the dominant directions in each location but also the mean wind speed values, as winds can be channelled or blocked by the different topographical features. Geographical differences are, for this reason, much more conspicuous than seasonal differences. Local relief is marked by two 

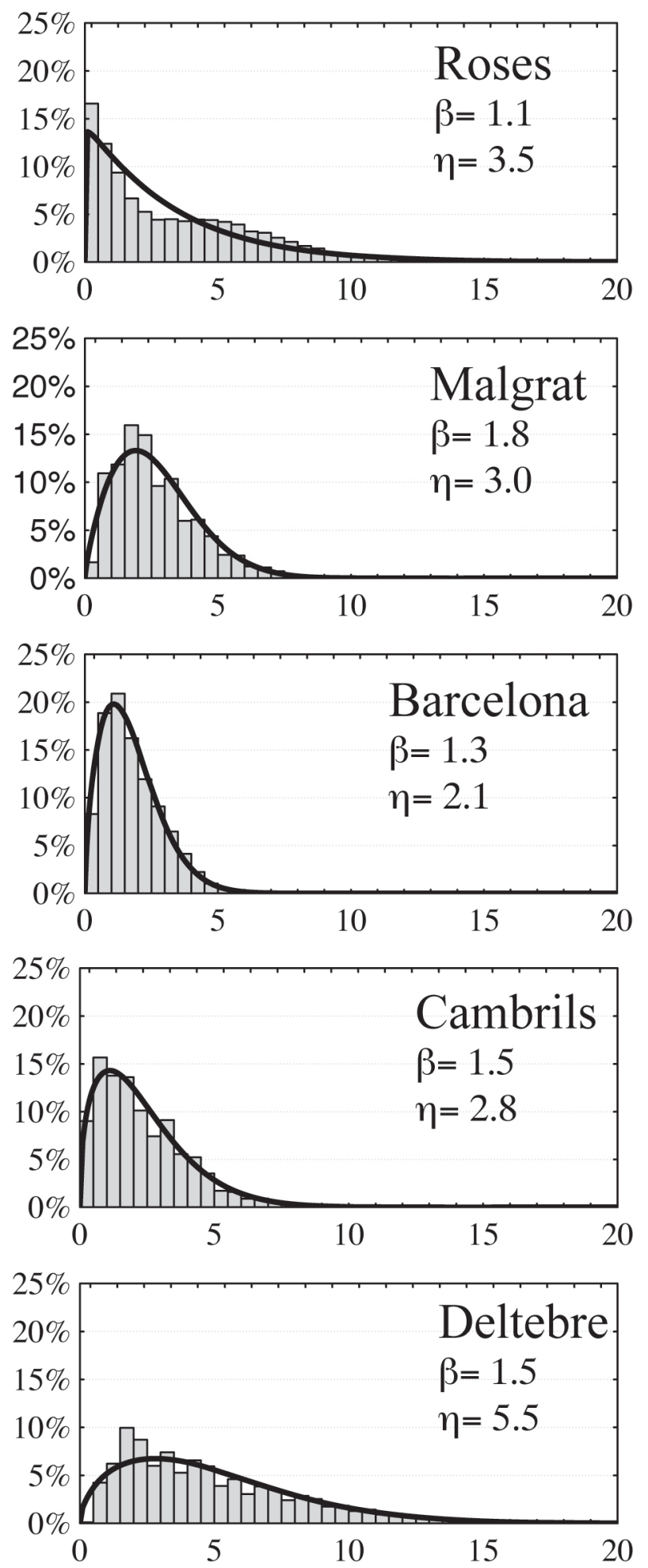

FIG. 3. - Histograms of frequency of wind data for the five meteorological stations used in this study. The line corresponds to the fitted Weibull frequency distributions obtained using the maximum likelihood method. Scale $(\eta)$ and shape $(\beta)$ parameters are shown for each station.

mountain ranges - the Serralada Litoral and the Serralada Prelitoral - that run parallel to the coast separated by a central depression. In the north and in the south the presence of the Pyrenees and the Ebro Valley respectively influence wind patterns greatly.

Inspecting Weibull probability plots of data (Fig. 3 ) for each different location showed that data fitted well to two-parameter Weibull distributions, except in the case of Roses, where the data were closer to an exponential distribution. The maximum likelihood parameter estimates for the Weibull distributions can be seen in Figure 3. Shape parameters are between 1 and 2 . Scale parameters vary between 2 and 6 . The highest wind speeds by far are found in Deltebre, and the lowest are found in Barcelona.

\section{Distribution of wind events}

The purpose of this part of the study was to establish the relationship between the frequency of an event (or its probability of occurring) and its intensity and persistence. The relationship of frequency with persistence was examined first. For each threshold within the studied range, frequency $(f)$ was found to be closely related to minimum persistence of events following a stretched exponential distribution of the form:

$$
f=\mathrm{b}_{1} \exp \left(-p^{\mathrm{b}_{2}}\right)
$$

where $p$ is minimum persistence of events, and $b_{1}$ and $b_{2}$ are parameters that are different for each threshold value. Stretched exponential probability density functions have been increasingly found in many fields (Frisch and Sornette, 1997; Laherrère and Sornette, 1998).

Then the relationship of the two parameters $b_{1}$ and $b_{2}$ in Eq. 4 with the threshold value $(t)$ was analyzed. The term $b_{1}$ fitted well to an exponential distribution, whereas $b_{2}$ was linearly related to the threshold value:

$$
\begin{gathered}
\mathrm{b}_{1}=\beta_{1} \exp \left(\beta_{2} t\right) \\
\mathrm{b}_{2}=\beta_{3}+\beta_{4} t
\end{gathered}
$$

Combining Eq. 4, 5 and 6 we obtain:

$$
f=\beta_{1} \exp \left(-\beta_{2} t\right) \exp \left(-p^{\beta_{3}+\beta_{4} t}\right)
$$

This model allowed us to predict the frequency of events that surpass a given threshold and a given persistence within the studied range.

Mean speed was calculated for each threshold and persistence class as the mean of all events with- 


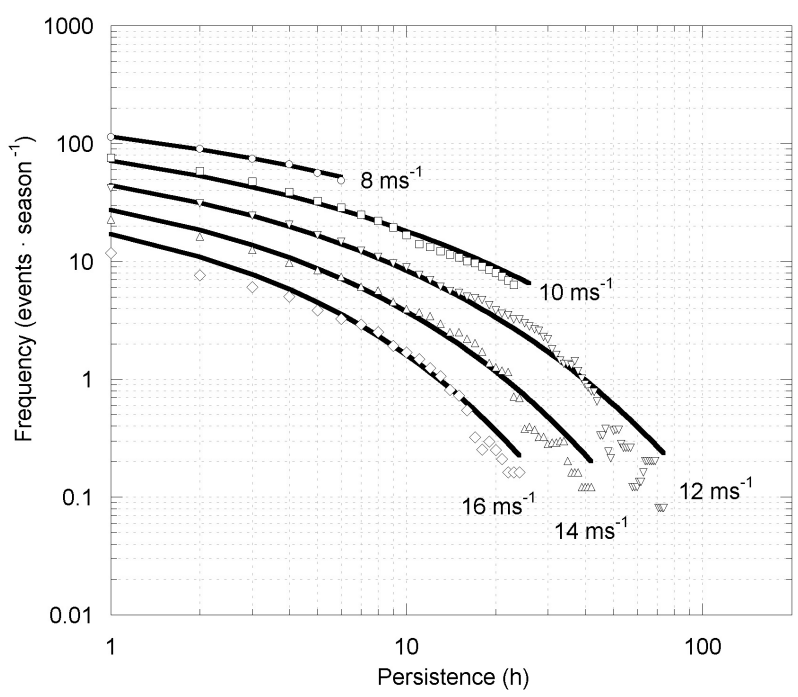

FIG. 4. - Logarithmic plot of frequency expressed as events per season against their persistence in hours for Deltebre station. Points are measured frequencies of events with the following mean values: 8 $\mathrm{ms}^{-1}$ (circles), $10 \mathrm{~ms}^{-1}$ (squares), $12 \mathrm{~ms}^{-1}$ (downward triangles), 14 $\mathrm{ms}^{-1}$ (upward triangles) and $16 \mathrm{~ms}^{-1}$ (diamonds). Lines are modelled frequencies using Eq.8.
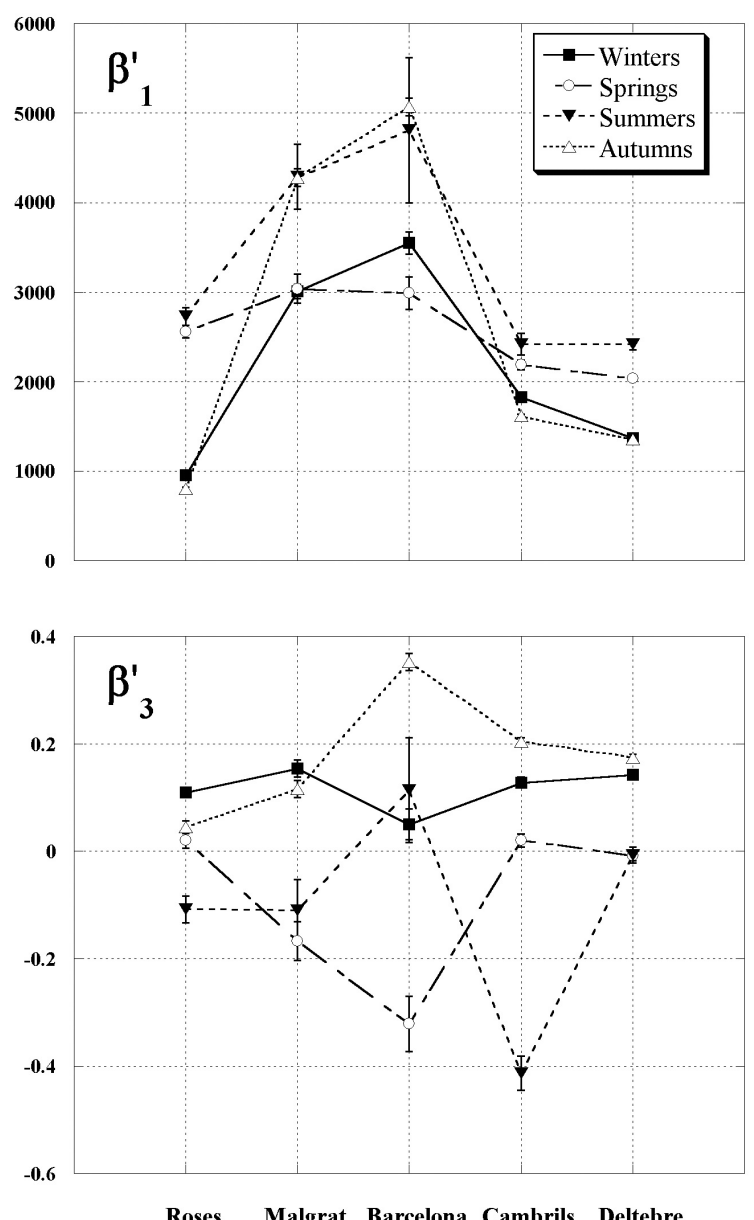

in that class. This mean speed value $(\bar{U})$ had a very strong linear relationship with the threshold value, so we can substitute threshold for mean wind velocity in Eq. 7:

$$
f=\beta_{1}^{\prime} \exp \left(-\beta_{2}^{\prime} \bar{U}\right) \exp \left(-p^{\beta_{3}^{\prime}+\beta_{4}^{\prime} \bar{U}}\right)
$$

Now, Eq. 8 relates the frequency of an event not with the threshold but with the mean value of the event. The best fit parameters of this model for the different series were found using nonlinear leastsquares data fitting (Gauss-Newton method). Initial values for the $\beta$ ' parameters were: $\beta_{1}{ }^{\prime}=1000 ; \beta_{2}{ }^{\prime}=-$ $0.5 ; \beta_{3}{ }^{\prime}=0, \beta_{4}{ }^{\prime}=0$. The models found fit very well to data, with $\mathrm{R}^{2}$ always $>90 \%$ and in most cases $>98 \%$. $\beta_{1}{ }^{\prime}$ ranged between 800 and $5000 ; \beta_{2}$ ' from 0.20 to $1.00 ; \beta_{3}$ ' from -0.41 to 0.35 , and $\beta_{4}$ ' from 0.02 to 0.21 . An example of the resulting distribution can be seen in Figure 4.

These $\beta$ ' parameters are statistical tools and have no easy physical interpretation due to the nonlinear
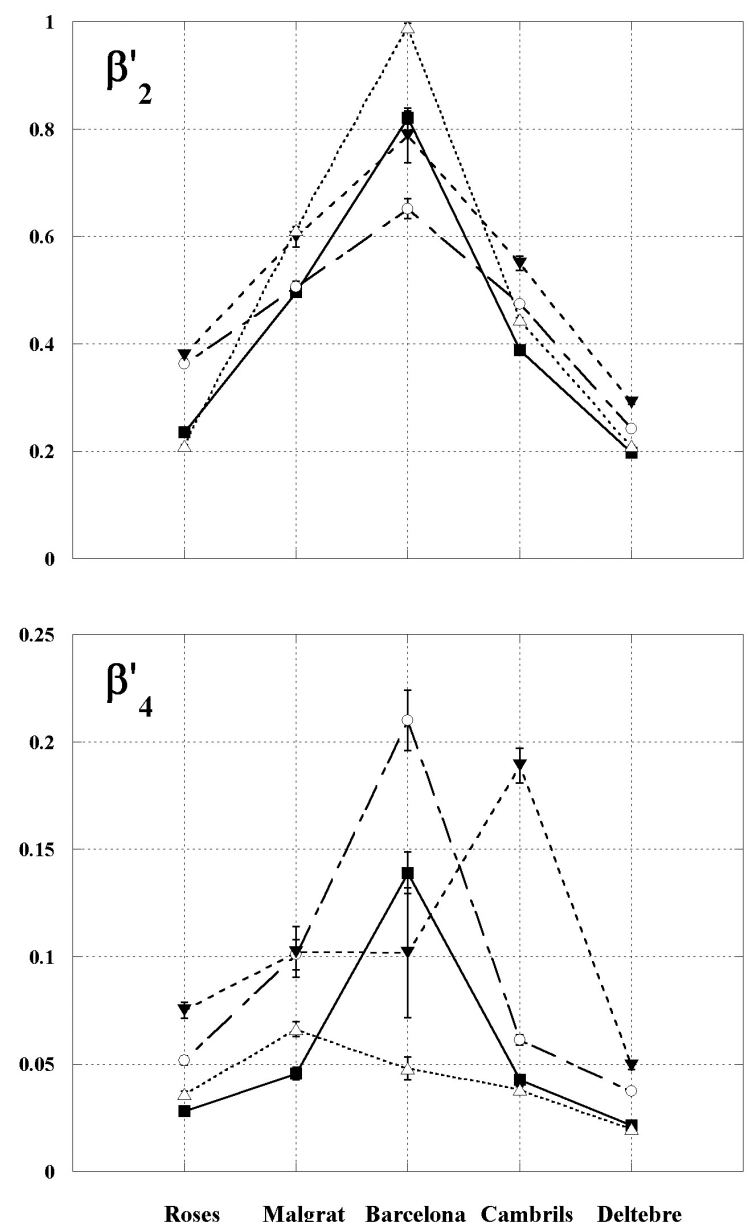

FIG. 5. - Parameter estimations for the Eq. 7 model. Error bars are 95\% confidence intervals. Squares: winter; circles: spring; full triangles: summer; empty triangles: autumn. 
nature of the distribution and cross-effects among the 4 parameters. $\beta_{1}$ ' determines the maximum frequency, i.e. the frequency of events when persistence and mean tend to $0 . \beta_{2}$ ' determines the steepness in relation to the mean, as the proportion of low to high threshold events increases with $\beta_{2}{ }^{\prime}$. The last two parameters, $\beta_{3}$ ' and $\beta_{4}$, determine frequency of events in relation to their persistence. Higher values of these parameters imply that frequency of events decreases faster with persistence. Note that for the range of thresholds studied in each series, the exponent $\left(\beta_{3}{ }^{\prime}+\beta_{4}{ }^{\prime} \bar{U}\right)$ is always positive. The larger the exponent the steeper the decrease of frequency against persistence. For weak events (that is, when $\bar{U}$ is small), $\beta_{3}{ }^{\prime}$ has a larger relative importance, whereas when $\bar{U}$ is high $\beta_{4}$ ' determines the shape of the distribution. In particular, $\beta_{4}$ ' parameterizes the effect of threshold in the persistence of events. When $\beta_{4}{ }^{\prime}$ is high, frequency of long events with respect to short events will decrease quickly as we consider higher and higher thresholds.

Parameter estimations for the final model (Eq. 8) can be seen in Figure 5. The highest maximum frequencies $\left(\beta_{1}{ }^{\prime}\right)$ are generally found in summer, but they decrease quickly with increasing thresholds $\left(\beta_{2}{ }^{\prime}\right)$, so that intense events are less frequent in summer than in any other season. Autumn and winter in general have longer events than spring and summer $\left(\beta_{3}\right.$ ' and $\left.\beta_{4}{ }^{\prime}\right)$. In summer and spring, as the exponent $\beta_{3}{ }^{\prime}$ is low, the decrease in frequency against persistence is smoother for weak events. However, $\beta_{4}$ ' is lower for autumn and winter, which means that for strong events it is in these seasons that frequency decays more slowly for increasing persistences. What this means is that long weak events are more frequent in spring and summer and that strong events are not only more frequent in autumn and winter but also longer.

The most pronounced differences are, however, geographical rather than seasonal. Both $\beta_{1}$, and $\beta_{2}$, have a maximum in Barcelona, where mean speed is lower. That means Barcelona is where frequency of intense events is lowest. Frequency and intensity of wind events seem to be positively related to a shape parameter (or to mean wind speed). The difference of Barcelona harbour compared to other locations is probably caused by a higher aerodynamic surface length owing to the proximity of the city.

\section{Turbulence}

Mean $\varepsilon$ values at $1 \mathrm{~m}$ depth for the different locations estimated from wind ranged between ca.

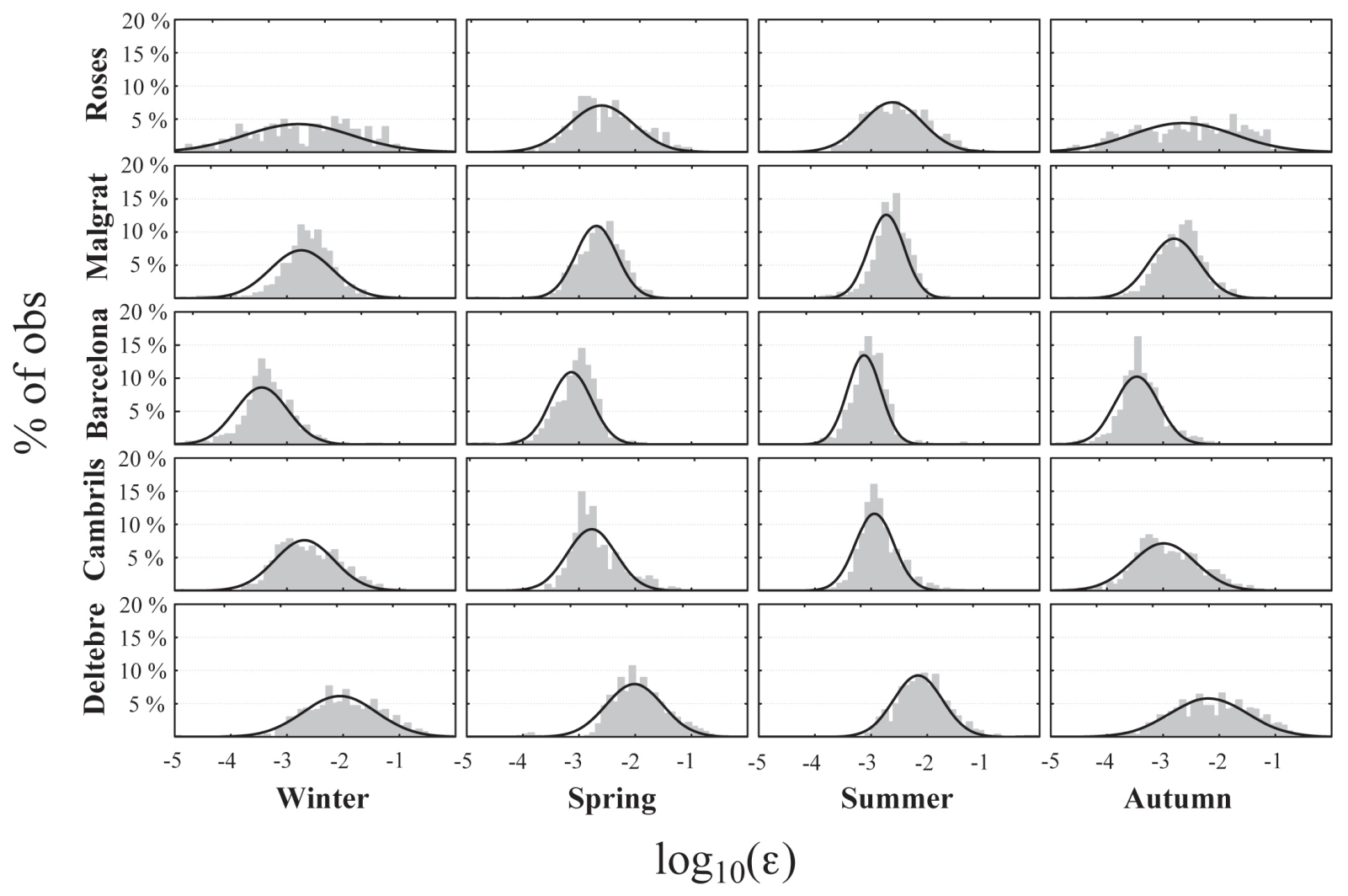

FIG. 6. - Frequency distributions of $\log 10(\varepsilon)$ estimated values at $1 \mathrm{~m}$ depth from wind velocity using model 6 in Mackenzie and Leggett (1993). Lines are fitted normal distributions obtained using the maximum likelihood method. 

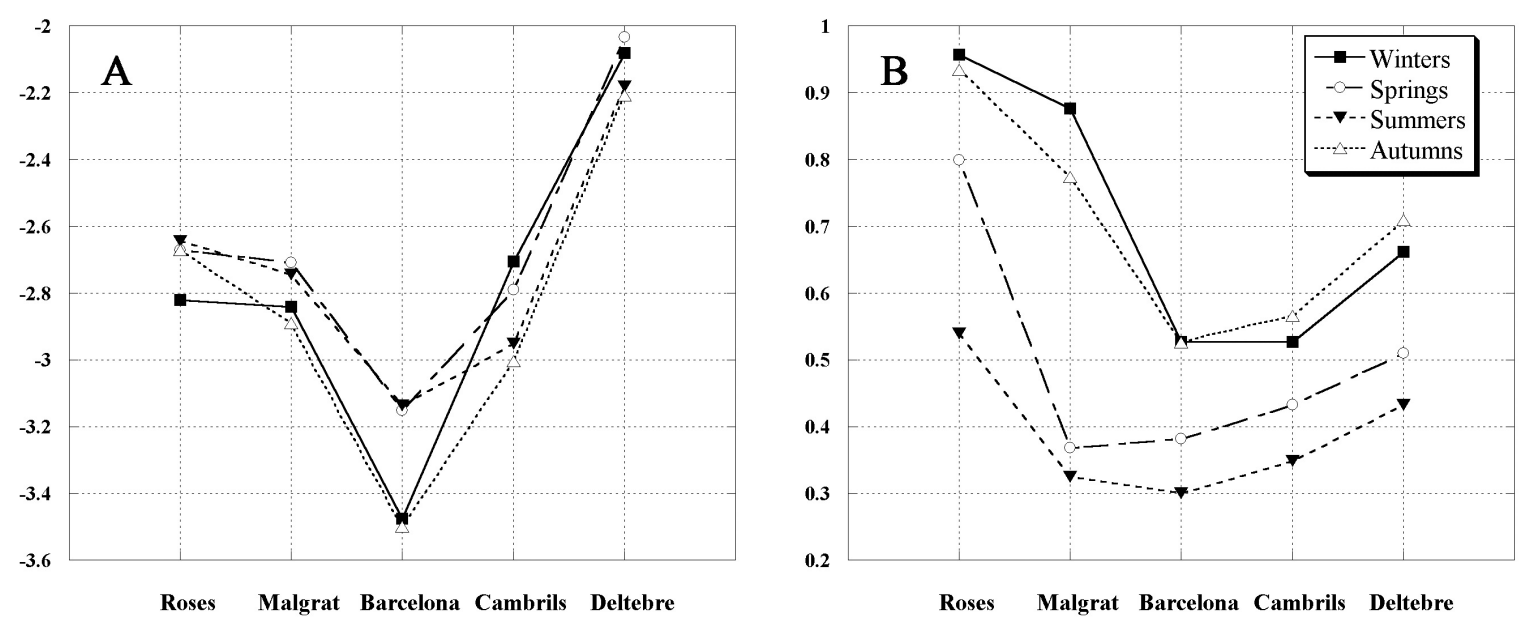

FIG. 7. - Mean (A) and variance (B) of $\log _{10}(\varepsilon)$ for the different locations and seasons. Symbols as in Fig. 5.

$3.5 \cdot 10^{-3}$ and $2.0 \cdot 10^{-2} \mathrm{~cm}^{2} \mathrm{~s}^{-3}$. The data clearly followed a dome-shaped frequency distribution (Fig. 6), although a Shapiro-Wilks normality test was not quite significant. An ANOVA was performed with season and location as categorical factors. The number of data points within each subpopulation was always large (more than 250), so even if they were not normally distributed the results were expected to be robust (Motulsky, 2003). Both the factors and their interaction were significant $(\mathrm{p}<0.01$ in all cases). Differences in mean values are very conspicuous between the different locations, whereas seasonal patterns, even if significant, are not so clear (Fig. 7A). Variances were non-homogeneous as determined with Barttlet's test. This could be an artefact due to the deviations from a Gaussian found in the subpopulations (Motulsky, 2003). Examining variances (Fig. 7B) shows consistent differences between different locations, as seen already for mean values (Fig. 7A), and also between seasons. Winter and autumn have consistently more dispersion than spring, and especially summer. This means that even if differences in turbulence mean values are hard to distinguish between seasons, there is still a higher frequency of high turbulence levels in winter and autumn. This is consistent with the seasonal differences found in the $\beta_{3}$, and $\beta^{\prime}{ }_{4}$ parameters in the wind events analysis.

\section{DISCUSSION}

\section{Applications of the model}

Models describing the frequency of wind events can be used as estimators of the probability of a wind event with a given minimum mean value and a given minimum persistence occurring within a relatively long period (a season or a year). Despite the large differences both in wind speed and direction between the different locations and seasons, the analysis conducted did not fail to fit a model to the data. It is therefore a powerful tool for assessing the frequency and intensity of wind events, and thus of turbulence variability. This descriptive capacity can be useful when dealing with wind-generated processes in which not only the threshold value is important but also the duration of the event, such as studies of gas transfer, including contaminants. This is the case of small-scale turbulence effects on plankton dynamics. Up to now most experimental work has been aimed at understanding how turbulence affects different communities and organisms, and determining the threshold values for these effects to appear. Therefore, in order to have detectable responses in the plankton community, experiments have generally been conducted under constant, relatively high turbulence conditions lasting for several days. However, when the aim is to reproduce turbulence as found in the sea we have to consider time as an important factor. Even if relatively high levels of turbulence, such as those used in many laboratory experiments, are common in the sea, organisms may rarely experience them for a long time (compare Fig. 6 with Fig. 1 in Peters and Marrasé, 2000).

Using models that relate wind and turbulence (such as those in Mackenzie and Legget, 1993), we can estimate the wind speed necessary to generate any given turbulence. The statistical models developed in the present study allow us to estimate the frequency of a wind event of given characteristics at 
TABLE 3. - Estimated frequency values (number of events per year) for a range of turbulence levels usual in experimental work, for persistences of 1, 2, 4 and 8 days, for each location.

\begin{tabular}{|c|c|c|c|c|c|c|c|}
\hline$\varepsilon\left(\mathrm{cm}^{2} \mathrm{~s}^{-3}\right)$ & $\bar{U}(\mathrm{~m} / \mathrm{s})$ & Persistence (d) & Roses & Malgrat & Barcelona & Cambrils & Deltebre \\
\hline \multirow[t]{4}{*}{$5.00 \mathrm{E}-03$} & 3.58 & 1 & $*$ & $187.3 \pm 66.7$ & $9.1 \pm 5.5$ & $110 \pm 24.5$ & $*$ \\
\hline & & 2 & $*$ & $113.9 \pm 61.1$ & $1.5 \pm 1.5$ & $63.2 \pm 21.7$ & $*$ \\
\hline & & 4 & $*$ & $62.5 \pm 48.5$ & $0.1 \pm 0.2$ & $32.1 \pm 16.3$ & $*$ \\
\hline & & 8 & $*$ & $30.2 \pm 33.1$ & $<0.1$ & $14.1 \pm 10.2$ & $*$ \\
\hline \multirow[t]{4}{*}{$1.00 \mathrm{E}-02$} & 4.61 & 1 & $163.7 \pm 32.2$ & $53.3 \pm 12.0$ & $0.2 \pm 0.4$ & $41.6 \pm 6.7$ & $*$ \\
\hline & & 2 & $101.4 \pm 30.1$ & $22.6 \pm 8.2$ & $<0.1$ & $18.4 \pm 4.8$ & $*$ \\
\hline & & 4 & $57.0 \pm 24.5$ & $7.6 \pm 4.2$ & $<0.1$ & $6.6 \pm 2.6$ & $*$ \\
\hline & & 8 & $28.5 \pm 17.3$ & $1.9 \pm 1.6$ & $<0.1$ & $1.8 \pm 11$ & * \\
\hline \multirow[t]{4}{*}{$5.00 \mathrm{E}-02$} & 8.30 & 1 & $15.4 \pm 2.2$ & $0.1 \pm 0.2$ & $<0.1$ & $0.5 \pm 0.6$ & $65.5 \pm 12.0$ \\
\hline & & 2 & $5 \pm 1.2$ & $<0.1$ & $<0.1$ & $<0.1$ & $31.1 \pm 9.0$ \\
\hline & & 4 & $1.1 \pm 0.4$ & $<0.01$ & $<0.01$ & $<0.01$ & $12.2 \pm 5.3$ \\
\hline & & 8 & $0.2 \pm 0.1$ & $<0.01$ & $<0.01$ & $<0.01$ & $<0.01$ \\
\hline \multirow[t]{4}{*}{$1.00 \mathrm{E}-01$} & 10.70 & 1 & $2.4 \pm 1.1$ & $<0.01$ & $<0.01$ & $<0.01$ & $20.1 \pm 2.8$ \\
\hline & & 2 & $0.4 \pm 0.3$ & $<0.01$ & $<0.01$ & $<0.01$ & $6.8 \pm 1.6$ \\
\hline & & 4 & $<0.01$ & $<0.01$ & $<0.01$ & $<0.01$ & $1.6 \pm 0.6$ \\
\hline & & 8 & $<0.01$ & $<0.01$ & $<0.01$ & $<0.01$ & $0.3 \pm 0.1$ \\
\hline \multirow[t]{4}{*}{$5.00 \mathrm{E}-01$} & 19.27 & 1 & $<0.01$ & $<0.01$ & $<0.01$ & $<0.01$ & $0.1 \pm 0.1$ \\
\hline & & 2 & $<0.01$ & $<0.01$ & $<0.01$ & $<0.01$ & $<0.01$ \\
\hline & & 4 & $<0.01$ & $<0.01$ & $<0.01$ & $<0.01$ & $<0.01$ \\
\hline & & 8 & $<0.01$ & $<0.01$ & $<0.01$ & $<0.01$ & $<0.01$ \\
\hline
\end{tabular}

* is under the mean wind value for this location.

a given location and see if it matches the time scales of planktonic organisms and their response to turbulence disturbance. Table 3 shows estimated frequency values for a range of turbulence levels normally used in experimental work. Note that occurrence and intensity of turbulence events are very locationdependent, as is the wind distribution pattern. Extrapolations to other locations are difficult to make and parameters must be locally estimated in order to apply the model. Data shown in Table 3 gives an idea of the vast range of situations one can find near shore.

This information provides a tool for putting previous biological work into an ecologically relevant context and addressing future studies on effects of turbulence, as they give us a range of situations an organism is likely to experience during its lifetime. In particular, these models can be used to design experiments dealing with effects of turbulence variability on plankton. This is especially interesting because most of the empirical knowledge on the topic comes from laboratory studies under controlled and generally constant turbulence levels (Peters and Redondo, 1997; Peters and Marrasé, 2000). The information of the frequency and intensity of events can help us address some pending questions. For example, is the mean turbulent field during a long time relevant for an organism's physiological response? Or is the maximum level encountered (even if this maximum level is not sustained for a time period compared to the processes of the organism) more important?
Another issue is how the time response of the different elements of the community can generate alternate scenarios. For example, usually the first element to respond positively to turbulence in laboratory experiments is phytoplankton, particularly diatoms. Then bacteria increase because of the released DOM but also because of changes in the structure of the food web (Peters et al., 1998), and organic matter enters the microbial food web. The duration of the turbulent event in this situation is critical, since it can determine the fate of the organic matter produced, which can either sediment out of the system or go up the food web to higher trophic levels.

The observed large geographical differences in wind temporal patterns in a coastal area can also have implications for the distribution of different biological assemblages and particularly for the appearance of blooms of some phytoplankton groups, such as dinoflagellates, with a certain sensitivity to turbulence (Margalef, 1978; Estrada and Berdalet, 1998). It may be interesting to compare the rate of appearance of these blooms with the frequency and intensity of wind events in particular locations. This may be of special concern when constructing harbours and breakers, locating aquaculture facilities and developing tourist areas, as these constructions alter the coastline further and hence the local input of energy from wind into turbulence. Taking into account the distribution of wind events and their dominant directions when designing and managing coastal areas can help to minimize the appearance of harmful algal blooms or hypoxic zones. 


\section{Limits and improvements}

These estimates of turbulence from wind speed are rather rough. Some improvements or refinements for further studies could include other possible sources of coastal turbulence. The model developed by Mackenzie and Leggett (1993) used here, included data from different hydrographic situations where it was known that wind was not the only source of turbulence. Even so, wind explained a significant amount of variability (54\%) of the data. However, there are other possible sources of energy especially near shore (Holman, 1995; St. Laurent et al., 2002), such as waves breaking, bottom shear stress or tidal energy. All these factors could increase our estimates of turbulence. On the other hand, the presence of a marked summer thermocline could reduce by an order of magnitude the level of dissipation down in the water column (Sherwin et al., 2002). The timescale of the model we used for the effect of waves breaking was 24 hours, which is much longer than the observation scales of enhanced dissipation rates caused by the process. Thus, we are assessing a mean state rather than the particular effect of a local wave breaking phenomenon. The turbulence that we estimate has to be seen as background turbulence, or a mean field, rather than as a precise instantaneous estimation. Therefore, time series of direct turbulence measurements are necessary, at least at some locations, in order to validate and fine tune model results from wind.

Another important source of variation in wind generated turbulence can be the distance from the coast. The meteorological stations used here are not located at sea but at some distance inland. In open water, wind speed tends to be higher as no obstacles are found. Therefore, we expect wind generated turbulence to be somewhat more important as we move away from the coastline. This hypothesis was tested using wind data from a meteorological station at the "Casablanca" oil drilling platform, located at about $35 \mathrm{~km}$ offshore from the southern Catalan coast. We applied the formula of Mackenzie and Leggett (1993) to assess the turbulence intensity at $1 \mathrm{~m}$ depth from daily averaged wind data. A T-test for dependent samples between the estimated turbulence data from "Casablanca" and from Deltebre, the closest of our meteorological stations and the one with the highest wind intensities, revealed that wind generated turbulence was significantly higher at "Casablanca" $(\mathrm{N}=283, \mathrm{p}<0.001)$.
Using wind direction can be another element of refinement in models. When turbulence close to the coast is considered, winds blowing onshore will generate larger waves than winds blowing from land (García and Ballester, 1984), since they have a longer fetch. This can translate into higher turbulence. In this study, all winds were considered equal.

Overcoming these uncertainties and fine-tuning the estimation of turbulence in water from wind data will require using long-time direct turbulence measurements. This contribution is a first approach to studying the temporal and spatial variability of small-scale turbulence. This is particularly useful for understanding plankton dynamics and can also be used by other fields of biological oceanography, as well as in air-seawater interaction studies and coastal engineering.

\section{ACKNOWLEDGEMENTS}

The "Servei Meteorològic de Catalunya" (http://www.meteocat.net/) gave technical advice and provided data for Roses, Malgrat de Mar, Cambrils and Deltebre. "Puertos del Estado" provided data on Barcelona. Jordi Font provided the data from the "Casablanca" oil drilling platform. O.G. had a Spanish CSIC-I3P fellowship sponsored by INNOVA oceanografía litoral, S.L. We thank Oswaldo López for his support, and Jordi Font and Celia Marrasé for helpful comments on earlier drafts of this manuscript. This study was supported by the EU project NTAP (EVK3-CT-2000-00022) and Spanish projects TURFI (REN2002-01591/MAR) and VARITEC (REN2003-08071-C02-01 / MAR). This is ELOISE contribution 519/40.

\section{REFERENCES}

Csanady, G.T. - 1989. Energy dissipation and upwelling in a western boundary current. J. Phys. Oceanogr., 19: 462-473.

D'Asaro, E.A. and G.T. Dairiki. - 1997. Turbulence intensity measurements in a wind-driven mixed layer. J. Phys. Oceanogr., 27: 2009-2022.

Dewey, R.K. and J.N. Moum. - 1990. Enhancement of fronts by vertical mixing. J. Geophys. Res., 95(C6): 9433-9445.

Dietze H., A. Oschlies and P. Kähler. - 2004. Internal-waveinduced and double-diffusive nutrient fluxes to the nutrientconsuming surface layer in the oligotrophic subtropical North Atlantic. Oc. Dyn., 54:1-7.

Estrada, M. and E. Berdalet. - 1998. Effects of turbulence on phytoplankton. In: D.M. Anderson, A.D. Cembella and G.M. Hallegraeff (eds.), Physiological Ecology of Harmful Algal Blooms, pp. 601-618. NATO ASI Series, G41.

Frisch, U. and D. Sornette. - 1997. Extreme deviations and applications. J. Phys. I France, 7: 1155-1171.

García, M.A. and A. Ballester. - 1984. Notas acerca de la meteo- 
rología y la circulación local en la región del delta del Ebro (1980-1981). Invest. Pesq., 48(3): 469-493.

Gargett, A.E. - 1989. Ocean Turbulence. Annu. Rev. Fluid. Mech., 21: 419-451.

Gargett, A.E. and P. Donaghay - 2003. Turbulence mixing and biophysical interactions. In: Regional Cabled Observatory Network (of Networks), Report of the Cabled Regional Observatory Workshop (http://www.geoprose.com/cabled_wksp/pdfs/reconn_rpt.3.2.04.pdf, downloaded 27/07/05).

Gemmrich, J.R. and D.M. Farmer. - 1999. Near-surface turbulence and thermal structure in a wind-driven sea. J. Phys. Oceanogr., 29: 480-499.

Gemmrich, J.R. and D.M. Farmer. - 2004. Near-surface turbulence in the presence of breaking waves. J. Phys. Oceanogr., 34: 1067-1086.

Holligan, P.M. - 1981. Biological implications of fronts on the Northwest European continental shelf. Phil. Trans. R. Soc. Lond. A, 302: 547-562.

Holman, R. - 1995. Nearshore processes. Rev. Geophys., 33(S1): 1237-1248.

Karp-Boss L., E. Boss and P.A. Jumars. - 1996. Nutrient fluxes to planktonic osmotrophs in the presence of fluid motion. Oceanogr. Mar. Biol. Annu. Rev., 34: 71-107.

Kiørboe, T. - 1997. Small-scale turbulence, marine snow formation, and planktivorous feeding. In: C. Marrasé E. Saiz and J.M. Redondo (eds.), Lectures on Plankton and Turbulence, Sci. Mar., 61(Suppl. 1): 141-158.

Laherrère, J. and D. Sornette. - 1998. Stretched exponential distributions in nature and economy: "fat tails" with characteristic scales. Eur. Phys. J. B, 2: 525-539.

Lazier, J.R.N. and K.H. Mann. - 1989. Turbulence and the diffusive layers around small organisms. Deep-Sea Res., 36: 1721-1733.

Maar, M., L. Arin, R. Simó, M.M. Sala, F Peters and C. Marrasé. 2002. Combined effects of nutrients and small-scale turbulence in a microcosm experiment. II. Dynamics of organic matter and phosphorus. Aquat. Microb. Ecol., 29: 63-72.

MacKenzie, B.R. and T. Kiørboe. - 2000. Larval fish feeding and turbulence: A case for the downside. Limnol. Oceanogr., 45(1): $1-10$.

MacKenzie, B.R. and W.C. Leggett. - 1993. Wind-based models for estimating the dissipation rates of turbulent energy in aquatic environments: empirical comparisons Mar. Ecol. Prog. Ser., 94: 207-216.

Margalef, R. - 1978. Life-forms of phytoplankton as survival alternatives in an unstable environment. Oceanol. Acta . 1: 493-509.

Marrasé, C., J.H. Costello, T. Granata and J.R. Strickler. - 1990. Grazing in a turbulent environment: Energy dissipation, encounter rates, and efficacy of feeding currents in Centropages hamatus. Proc. Natl. Acad. Sci. USA, 87: 16531657.

McWilliams, J.C., P.P. Sullivan, and C Moeng. - 1997. Langmuir turbulence in the ocean. J. Fluid Mech., 334: 1-30.

Motulsky, H. - 2003. Intuitive biostatistics. Oxford University Press, New York.

Oakey, N.S. and J.A. Elliott. - 1982. Dissipation within the surface mixed layer, J. phys. Oceanogr., 12: 171-185.

Osborn, T.R. and W.R. Crawford. - 1980. An airfoil probe for measuring turbulent velocity fluctuations in water. In: L. Hasse, F. Dobson and R. Davis (eds.), Instruments and Methods of air- sea interaction, pp. 369-386. Plenum Press.New York.

Peters, F. and C. Marrasé. - 2000. Effects of turbulence on plankton: an overview of experimental evidence and some theoretical considerations. Mar. Ecol. Prog. Ser., 205: 291-306.

Peters, F., C. Marrasé, J.M. Gasol, M.M. Sala and L. Arin. - 1998. Effects of turbulence on bacterial growth mediated through food web interactions. Mar. Ecol. Prog. Ser., 172: 293-303.

Peters, F. and J.M. Redondo. - 1997. Turbulence generation and measurement: application to studies on plankton. In: C. Marrasé, E. Saiz and J.M. Redondo (eds.), Lectures on Plankton and Turbulence, Sci. Mar., 61(Suppl. 1): 205-228.

Pingree, R.D., G.T. Mardell and D.E. Cartwright. - 1981. Slope turbulence, internal waves and phytoplankton growth at the Celtic Sea shelf-break (and discussion). Phil. Trans. R. Soc. Lond. A, 302: 663-682.

Reiter, E.R. - 1975. General Description of the Meteorological Processes. Part 1, Handbook for Forecasters in the Mediterranean: Weather Phenomena of the Mediterranean Basin. Nav. Environ. Predict. Res. Facil. Tech. Nav. Posgrad. Sch., Monterey, California.

Rothschild, B.J. and T.R. Osborn. - 1988. Small-scale turbulence and plankton contact rates. J. Plankton Res., 10: 465-474.

Ruiz, J. - 1996. The role of turbulence in the sedimentation loss of pelagic aggregates from the mixed layer. J. Mar. Res., 54: 385406

Ruiz, J., D. Macías and F. Peters. - 2004. Turbulence increases the average settling velocity of phytoplankton cells. Proc. Natl. Acad. Sci. USA, 101(51): 17720-17724.

Saiz, E. and T. Kiørboe. - 1995. Predatory and suspension feeding of the copepod Acartia tonsa in turbulent environments. Mar. Ecol. Prog. Ser., 122: 147-158.

Sherwin, T.J., M.E. Inall and R. Torres. - 2002. The seasonal and spatial variability of small-scale turbulence at the Iberian margin. J. Mar. Res., 60 (1): 73-100.

St.Laurent, L.C., H. L. Simmons, and S.R. Jayne - 2002. Estimating tidally driven mixing in the deep ocean. Geophys. Res. Lett. 29(23): 1-4

Stips. A., H. Burchard, K. Bolding, H. Prandke, A. Simon, A. Wüest. - 2005. Measurement and simulation of viscous dissipation in the wave affected surface layer. Deep-Sea Res. II, 52: $1133-1155$.

Stull, R.B. - 1988. An introduction to boundary layer meteorology. Atmospheric sciences library. Vol. 13. Kluwer Academic Publishers. Dordrecht, Netherland.

Sun, H. and E. Kunze. - 1999. Internal wave-wave interactions. Part II: Spectral energy transfer and turbulence production. J. Phys. Oceanogr., 29: 2905-2919.

Terray, E.A., M.A. Donelan, Y.C. Agrawal, W.M. Drennan, K.K Kahma, A.J. Williams III, P.A. Hwang and S.A. Kitaigorodskii. - 1996. Estimates of kinetic energy dissipation under breaking waves. J. Phys. Oceanogr., 26: 792-807.

Troen, I. and E.L. Petersen. - 1989. European Wind Atlas. Ris $\varnothing$ National Laboratory, Ris $\varnothing$, Denmark.

Turner, J.S. - 1973. Buoyancy effects in fluids. Cambridge University Press.

Yen, J., M.J. Weissburg and H. Doall. - 1998. The fluid physics of signal reception by mate-tracking copepods. Phil. Trans. R. Soc. Lond., 353: 787-804.

Scient. ed.: T. Kiørboe 